\title{
Premature failure of an additively manufactured material
}

\author{
Zhi Wang ${ }^{1}$, Meishen Xie', Yuanyuan $\mathrm{Li}^{1,2}$, Weiwen Zhang ${ }^{1}$, Chao Yang ${ }^{1}$, Lauri Kollo ${ }^{3}$, Jürgen Eckert ${ }^{4,5}$ and \\ Konda Gokuldoss Prashanth 3,4,6
}

\begin{abstract}
Additively manufactured metallic materials exhibit excellent mechanical strength. However, they often fail prematurely owing to external defects (pores and unmelted particles) that act as sites for crack initiation. Cracks then propagate through grain boundaries and/or cellular boundaries that contain continuous brittle second phases. In this work, the premature failure mechanisms in selective laser melted (SLM) materials were studied. A submicron structure was introduced in a SLM $\mathrm{Ag}-\mathrm{Cu}-\mathrm{Ge}$ alloy that showed semicoherent precipitates distributed in a discontinuous but periodic fashion along the cellular boundaries. This structure led to a remarkable strength of $410 \pm 3 \mathrm{MPa}$ with $16 \pm 0.5 \%$ uniform elongation, well surpassing the strength-ductility combination of their cast and annealed counterparts. The hierarchical SLM microstructure with a periodic arrangement of precipitates and a high density of internal defects led to a high strain hardening rate and strong strengthening, as evidenced by the fact that the precipitates were twinned and encircled by a high density of internal defects, such as dislocations, stacking faults and twins. However, the samples fractured before necking owing to the crack acceleration along the external defects. This work provides an approach for additively manufacturing materials with an ultrahigh strength combined with a high ductility provided that premature failure is alleviated.
\end{abstract}

\section{Introduction}

Additive manufacturing (AM) technologies, like laser powder bed fusion (LPBF) and selective laser melting, have recently attracted great attention since they can process a wide spectrum of materials with improved or at least similar mechanical properties as those of their cast counterparts $^{1-4}$. However, the microstructures are anisotropic, and different microstructural features and morphologies are observed at different length scales ${ }^{5}$. For instance, typical features of selective laser melting, like melting tracks, are observed at the macroscopic and microscopic scales, and the individual phases and their distributions appear at the microscopic scale and

Correspondence: Zhi Wang (wangzhi@scut.edu.cn) or Meishen Xie (msmesxie@mail.scut.edu.cn) or Konda Gokuldoss Prashanth (prashanth. konda@taltech.ee)

${ }^{1}$ Guangdong Key Laboratory for Advanced Metallic Materials Processing, South China University of Technology, 510641 Guangzhou, China

${ }^{2}$ State Key Laboratory of Materials Processing and Die \& Mould Technology, Huazhong University of Science and Technology, 430074 Wuhan, China Full list of author information is available at the end of the article nanoscale ${ }^{6}$. The microstructure is typically anisotropic along the length of the samples, especially if the samples are long and if base plate heating is employed ${ }^{7}$. Such anisotropies in the microstructure at different length scales make it difficult to predict the mechanical properties of SLM samples ${ }^{7}$. In addition, SLM samples exhibit non-equilibrium phases due to fast cooling and possess a high strength at the expense of the ductility ${ }^{8}$. The microstructural development is based more on the kinetics of the process than its thermodynamics because of the high cooling rates and the undercooling involved with the selective laser melting process ${ }^{8,9}$. Even though SLM materials generally exhibit a higher yield and tensile strengths than their cast counterparts, they still often fail well below their expected strengths; thus, there is substantial room for improvement. This was exemplified for $\mathrm{Al}-12 \mathrm{Si}$ and $\mathrm{AlMgSi}$ alloys ${ }^{10,11}$, where the work hardening curve did not meet the tensile stress-strain curve, suggesting that the materials failed before necking. The high degree of internal defects and introduction of new 
external defects played a crucial role in limiting the materials from reaching their expected strength, even though high strengths were reached. Such behavior is termed premature failure, and most SLM samples tend to fail before necking ${ }^{4}$. Premature failure has become very common in SLM materials, where otherwise excellent mechanical properties (theoretically) may be achieved. The premature failure is due to the presence of external defects (pores and unmelted particles) that act as sites for crack initiation; the cracks then propagate through the grain boundaries and/or cellular boundaries. Materials fabricated by selective laser melting typically have a unique metastable cellular microstructure, such as Al$12 \mathrm{Si}$, AlSi10Mg, CoCrMo, and $316 \mathrm{~L}^{12-15}$. The cellular boundaries usually constitute a nearly connected layer ${ }^{12}$ that can accelerate crack propagation. To reap the complete benefits of SLM materials in terms of their excellent mechanical properties, there is an urgent need to investigate the causes of premature failure and to derive measures for overcoming premature failure in these materials, which is vital for realizing selective laser melting as a future manufacturing process.

Here, we report the fundamental mechanisms behind premature failure in an additively manufactured metallic material. Ag-Cu-Ge was chosen because $\mathrm{Ag}-\mathrm{Cu}$ does not form any complex intermetallic phases for small $\mathrm{Cu}$ contents and $\mathrm{Cu}-\mathrm{Ge}$ mostly forms the $\mathrm{Cu}_{3} \mathrm{Ge}$ and/or $\mathrm{Cu}_{5} \mathrm{Ge}$ phases that precipitate in the Ag-based matrix ${ }^{16}$. Hence, the formation of complex intermetallic phases and their detrimental effects can be avoided. Moreover, the Ag matrix has a fcc structure and exhibits ductile behavior when deformed ${ }^{17}$. The mechanisms for premature failure are devised, and a road map is laid to avoid premature failure in SLM materials. A nominal amount of Ge $(1 \pm 0.2$ wt.\%) was added into the Ag-7.5 wt.\% $\mathrm{Cu}$ alloy to aid in the precipitation of the $\mathrm{Cu}_{3} \mathrm{Ge}$ and/or $\mathrm{Cu}_{5} \mathrm{Ge}$ phases. In addition, Ge promotes cosegregation of $\mathrm{Cu} / \mathrm{Ge}$ onto the boundaries of the primary $\mathrm{Ag}$ grains ${ }^{12}$. The eutectic formation of $\alpha+\beta$ leads to a submicron-sized mesostructure, similar to that for $\mathrm{Cu}-10 \mathrm{Sn}$ alloys produced by selective laser melting both in terms of the phases and their morphology ${ }^{18}$. The formation of a eutectic microstructure from the melt is observed, where the primary phase, $\mathrm{Ag}$-rich $(\alpha)$, forms the matrix and the secondary $\mathrm{Cu}$-rich phases $\left(\mathrm{Cu}_{3} \mathrm{Ge}\right.$ and $\mathrm{Cu}_{5} \mathrm{Ge}$ ) precipitate in a periodic arrangement in the matrix. Such fine mesostructures are attributed to the large constitutional supercooling and the high velocity of the solidification front observed during selective laser melting.

\section{Materials and methods Sample preparation}

A prealloyed gas atomized powder of sterling silver (Ag, $\mathrm{Cu}-7.5$ wt.\% and $\mathrm{Ge}-1$ wt.\% $-99.99 \%$ purity) with a spherical morphology (size distribution of $40 \pm 10 \mu \mathrm{m}$ ) was used in this study. The powder was purchased from LEGOR GROUP POWMET. A Realizer SLM50 device was used to fabricate almost fully dense (with $<1 \%$ porosity) sterling silver samples with the following parameters: a layer thickness of $30 \mu \mathrm{m}$, laser current of $4000 \mathrm{~mA}$, laser scan speed of $0.2 \mathrm{~m} / \mathrm{s}$, and hatch spacing of $70 \mu \mathrm{m}$. At least 20 tensile samples were prepared, and the size and shape of the samples are given in the Supplementary Information. Bulk counterparts were produced by casting so that the microstructure and mechanical properties of the differently produced materials could be compared. Pure elements (99.99\%) were melted in a graphite crucible at $927 \mathrm{~K}$ in a medium-frequency vacuum induction furnace and cast in the form of ingots $(15 \mathrm{~mm}$ in diameter and $150 \mathrm{~mm}$ in height) into a graphite mold, followed by water quenching.

\section{Microstructure analysis}

The density of the samples was evaluated by the Archimedes principle. X-ray diffraction (XRD) was performed using a D8-Advance diffractometer (Bruker, Karlsruhe, Germany) with $\mathrm{Cu}-\mathrm{K} \alpha$ radiation $(\lambda=0.154056 \mathrm{~nm})$. A step size of $0.0131^{\circ}$ was used with a time of $5 \mathrm{~s}$ per step. The microstructural studies were conducted using scanning electron microscopy (SEM, Nova 2000, FEI, Germany) on an instrument equipped with an HKL-Technology electron backscattered diffraction (EBSD) detection system and analytical transmission electron microscopy (TEM, Tecnai G2 F20, FEI, Germany) on an instrument equipped with energy-dispersive X-ray spectroscopy (EDS). The SEM specimens were mirror polished and etched with a 50 vol.\% $\mathrm{H}_{2} \mathrm{O}_{2}+25$ vol.\% $\mathrm{NH}_{4} \mathrm{OH}+25$ vol.\% $\mathrm{H}_{2} \mathrm{O}$ solution for 5-10 s. For the EBSD analysis, the scanning step size was $0.25 \mu \mathrm{m}, 0.3 \mu \mathrm{m}$ and $0.7 \mu \mathrm{m}$ along the Z-plane, Y-plane and $\mathrm{X}$-plane, respectively, and $0.1 \mu \mathrm{m}$ and $0.04 \mu \mathrm{m}$ of the columnar grains and fine equiaxed grains were checked, respectively. The EBSD data analysis was carried out using Channel 5 software.

\section{Tensile tests}

Uniaxial tensile tests were conducted on an INSTRON 5565 device at ambient temperature using samples with a length of $52 \mathrm{~mm}$, diameter of $3.5 \mathrm{~mm}$ and height along the gauge length of $21 \mathrm{~mm}$. A strain rate of $1.0 \times 10^{-3} \mathrm{~s}^{-1}$ was employed. At least three tensile samples were tested for each condition, where the yield strength and strain hardening rate were nearly similar and the uniform elongation had an error of $<1 \%$, indicating that a high degree of repeatability was obtained for both the SLM and cast samples within the experimental limits considered.

\section{Results and discussion}

The microstructure of the SLM samples is complex and anisotropic because different features and morphologies are 
observed at different length scales (Fig. 1 and Supplementary Fig. 2). Low-magnification scanning electron microscopy and electron backscatter diffraction images (Supplementary Fig. $2 \mathrm{a}-\mathrm{c}$ ) reveal the following features: laser tracks, melt pool geometry and a layered morphology, which are typical for SLM samples. At the macroscale, typical melt tracks are observed, corroborating the laser melting sequence (Supplementary Fig. 2a-c). The Y-plane shows a long scan vector with a thickness of $90 \pm 20 \mu \mathrm{m}$. An overlap of $20 \pm 5 \mu \mathrm{m}$ is observed between two laser tracks and dictated by the hatch spacing, which is utilized to produce continuous samples without external defects, like pores. On the other hand, half-cylindrical melt pools with a height of $30 \pm 15 \mu \mathrm{m}$ are visible along the X-plane (Supplementary Fig. 2a), corresponding to the layer thickness. A close look at the microstructure reveals the presence of three different regions with three different microstructural morphologies (Supplementary Fig. 2d-g): (a) fine equiaxed,
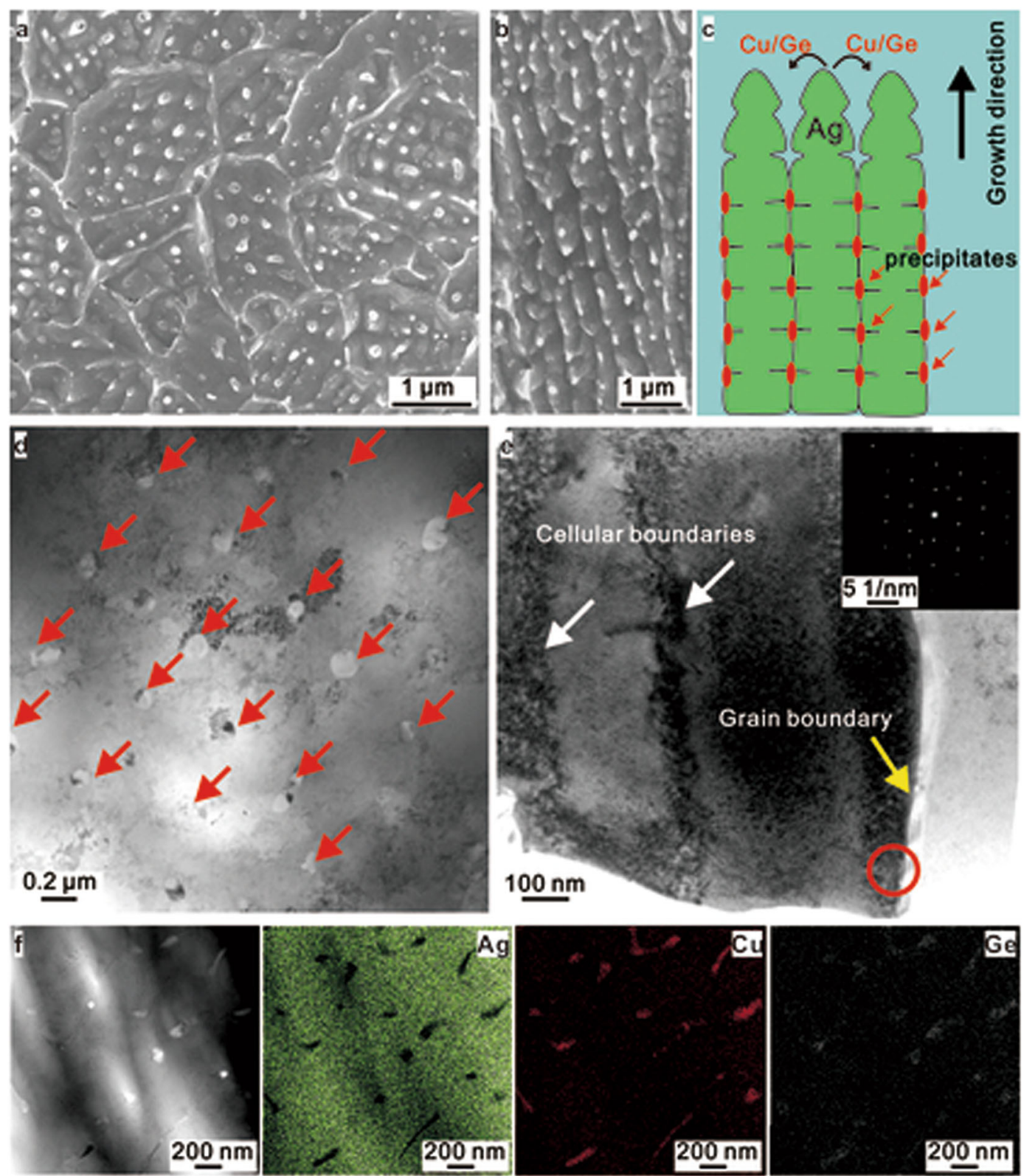

Fig. 1 Typical microstructure of the SLM Ag-Cu-Ge alloy. a, b Scanning electron microscopy (SEM) image showing the coarse equiaxed and columnar grains. c Schematic illustration showing the typical microstructure of the columnar grains with discontinuous Cu-rich precipitates. d Transmission electron microscopy (TEM) micrographs revealing discontinuous Cu-rich precipitates with periodic arrangements. e TEM micrographs showing dislocations distributed along the cellular and grain boundaries. f TEM image and corresponding energy-dispersive X-ray spectroscopy (EDS) mapping analysis showing the discontinuous Cu-rich precipitates. 
(b) columnar and (c) coarse equiaxed grains, similar to the microstructures observed in solid solutions when solidified as ingots (Supplementary Fig. 3). The fine equiaxed grains (with a diameter of $0.8 \pm 0.4 \mu \mathrm{m}$, see Supplementary Fig. 4) develop along the boundary of the melt, which is in contact with the solid material and where the heat extraction is maximum, leading to rapid quenching. The fine equiaxed grains have a width of $5 \pm 1 \mu \mathrm{m}$, which is one-fourth the width of the hatch overlap. The fine equiaxed grains are followed by columnar grains with an equivalent diameter of $5 \pm 2 \mu \mathrm{m}$, a width of $2.4 \pm 1.1 \mu \mathrm{m}$ and a thickness of $16 \pm$ $8 \mu \mathrm{m}$, calculated by the physical area. The columnar grains grow along the [100] crystallographic direction from the fine equiaxed grains. Coarse equiaxed grains (diameter $2 \pm$ $1 \mu \mathrm{m}$, length $8 \pm 2 \mu \mathrm{m}$ ) are observed beside the columnar grains; these results are similar to those for conventional ingot solidification of solid solutions, except for the differences in their length scale. The $\mathrm{Ag}-\mathrm{Cu}$ phase diagram (Supplementary Fig. 5) shows a eutectic reaction at $28.1 \mathrm{wt}$. $\%{ }^{19}$. The solubility of $\mathrm{Cu}$ in $\mathrm{Ag}$ is $8.8 \mathrm{wt} . \%$ at a eutectic temperature of $779^{\circ} \mathrm{C}$. During solidification as the temperature drops towards room temperature, the solubility of $\mathrm{Cu}$ in $\mathrm{Ag}$ decreases, and the solubility of $\mathrm{Cu}$ in $\mathrm{Ag}$ at room temperature is zero. The presence of Ge does not interfere with the solubility limits of $\mathrm{Cu}$ in $\mathrm{Ag}$, except for the formation of $\mathrm{Cu}$-rich phases $\left(\mathrm{Cu}_{3} \mathrm{Ge} \text { and } \mathrm{Cu}_{5} \mathrm{Ge}\right)^{16}$. The observed melt pool is generally narrow $(\sim 100 \mu \mathrm{m}$ in width) and shallow $(\sim 30 \mu \mathrm{m}$ in depth). The rapid cooling rates observed from the selective laser melting process and supercooling lead to the formation of a supersaturated solid solution of $\mathrm{Cu}$ in $\mathrm{Ag}$. This is because the solidification front moves at a fast rate and the narrow and shallow melt pool does not allow time for the $\mathrm{Cu}$ to diffuse out of the $\mathrm{Ag}$ completely ${ }^{12}$. Hence, some of the $\mathrm{Cu}$ is engulfed within the $\mathrm{Ag}$, forming a supersaturated solid solution. The amount of $\mathrm{Cu}$ in the Ag matrix was $\sim 3.0 \pm 0.7 \mathrm{wt} . \%$ in the present SLM specimens measured by EDS combined with transmission electron microscopy. The rapid cooling rate during the selective laser melting process may lead to the formation of supersaturated solid solutions in $\mathrm{Ag}-\mathrm{Cu}$ alloys ${ }^{20}$. However, in this SLM Ag-Cu alloy, the supersaturation is only $\sim 3 \mathrm{wt}$. $\% \mathrm{Cu}$. The alloy has undergone competitive supersaturation during the solidification process, where the supersaturation of $\mathrm{Cu}$ in $\mathrm{Ag}$ depends not only on the cooling rate of the process but also on other factors, like: (1) the activity of $\mathrm{Ag}$ and $\mathrm{Cu},(2)$ the activity of $\mathrm{Cu}$ and $\mathrm{Ge}$ and (3) the activity of $\mathrm{Ag}$ and Ge. First, when the supersaturated phases are formed, not only $\mathrm{Cu}$ is entrapped but also some $\mathrm{Ge}$ is entrapped within the Ag matrix. This behavior changes the dynamics of $\mathrm{Cu}$ and $\mathrm{Ag}$, where the amount of supersaturated $\mathrm{Cu}$ in $\mathrm{Ag}$ is reduced, irrespective of the observed rapid quenching. Second, $\mathrm{Cu}$ and $\mathrm{Ge}$ react strongly to form $\mathrm{Cu}_{\mathrm{x}} \mathrm{Ge}$ precipitates, and hence, some $\mathrm{Cu}$ is consumed during the solidification process, such as when $\mathrm{Cu}$ segregates into the cellular boundaries from the Ag (confirmed by Supplementary Fig. 6). This is because the solubility of $\mathrm{Cu}$ in $\mathrm{Ag}$ decreases with temperature, and at room temperature, the solubility is almost zero. In addition, Ge also behaves in the same way as Ag, whose solubility deceases with temperature. Third, the recycled heat in the built layers during the selective laser melting process leads to the diffusion of some $\mathrm{Cu}$ out of $\mathrm{Ag}$. The lattice parameters of $0.40805 \mathrm{~nm}$ and $0.40622 \mathrm{~nm}$ were observed for a Ag matrix fabricated by selective laser melting and casting, respectively, and were calculated from the XRD patterns, as shown in Supplementary Fig. 7. They are smaller than the lattice parameter of pure $\mathrm{Ag}$, which is $4.0855 \mathrm{~nm}^{21}$; this may be because the lattice parameter of Ag decreases with the formation of a supersaturated solid solution of $\mathrm{Cu}$ in $\mathrm{Ag}$, where $\mathrm{Cu}$ has a smaller atomic radius $(0.128 \mathrm{~nm})$ than $\mathrm{Ag}$ $(0.144 \mathrm{~nm})^{22}$. The residual $\mathrm{Cu}(\sim 4.5 \mathrm{wt} . \%)$ reacts with $\mathrm{Ge}$ to form $\mathrm{Cu}$-rich phases, in which $\mathrm{Cu}_{5} \mathrm{Ge}$ is the main phase and a number of $\mathrm{Cu}_{3} \mathrm{Ge}$ precipitates are also observed (as seen in Supplementary Fig. 8). The $\mathrm{Cu}_{3} \mathrm{Ge}$ phase is an ordered phase (crystal system: ordered orthorhombic, space group: Pmmn (59) ${ }^{23}$, and it is difficult to distinguish it from the $\mathrm{Cu}_{5} \mathrm{Ge}$ (crystal system: hexagonal, space group: $\mathrm{P} 63 / \mathrm{mmc}$ $(194))^{24}$ in the TEM micrographs, as shown in Fig. 1d. The microstructure consists of $\alpha-\mathrm{Ag}$-rich and $\mathrm{Cu}$-rich precipitates that solidify from the melt. The $\mathrm{Cu}$-rich precipitates (size: $\sim 0.1 \mu \mathrm{m}$ ) segregate along the grain boundaries of the $\alpha-\mathrm{Ag}$ and subsequently precipitate in the interior of the $\alpha$-Ag grains (along the cellular boundaries) as discontinuous bright islands arranged in a periodic fashion (Fig. 1). Cu-rich precipitates with a discontinuous but periodic distribution are confirmed by EDS mapping (Fig. 1f) and are rich in $\mathrm{Cu}$ and $\mathrm{Ge}$ but lack Ag. Structural characterization of the samples by XRD shows the presence of a single-phase $\alpha$-Ag solid solution (Supplementary Fig. 7). No secondary phases are observed apart from the primary $\alpha$-phase (since the amount of free residual $\mathrm{Cu}$ and $\mathrm{Ge}$ is $<5$ wt.\% and no peaks of $\mathrm{Cu}, \mathrm{Ge}, \mathrm{Cu}_{3} \mathrm{Ge}$, or $\mathrm{Cu}_{5} \mathrm{Ge}$ are visible in the XRD pattern). On the other hand, the cast sample contains both $\alpha-\mathrm{Ag}$ and $\mathrm{Cu}$-rich phases, which was also confirmed by the eutectic microstructure (a mixture of $\alpha-\mathrm{Ag}$ and $\beta-\mathrm{Cu}$ ) observed in the microscopy images (Supplementary Fig. 9). The solidification of Ag-Cu-Ge is similar to that of $\mathrm{Al}-12 \mathrm{Si}$, where the material with a low melting point solidifies first and the phase with a relatively high melting point solidifies later along the boundaries of the first phase, leading to a cellular structure ${ }^{25}$. Similarly, in the present material, low-melting-point Ag solidifies first and the relatively high-melting-point $\mathrm{Cu}$-rich precipitates in the Ag matrix (semi-coherently) solidify in a random but periodic arrangement.

The discontinuous bright $\mathrm{Cu}_{5} \mathrm{Ge}$ precipitates show semicoherent interfaces. There is a $\sim 15 \%$ misfit between the $\{111\} \alpha-\mathrm{Ag} \|\{10 \overline{1} 1\}$ hcp $\mathrm{Cu}_{5} \mathrm{Ge}$ planes, which leads to 
periodic misfit dislocations, as shown in Fig. $3 \mathrm{f}$ and Supplementary Fig. 10. TEM characterization of the SLM samples reveals a high density of internal defects, such as dislocations, stacking faults (SFs) and twins, as shown in Fig. 1d, e and Supplementary Fig. 2h-k. The dislocations are tangled along the cellular and/or grain boundaries (Supplementary Fig. 2h, e). The observed dislocation density $\left(\sim 2.5 \times 10^{14} \mathrm{~m}^{-2}\right)$ is two orders of magnitude higher than that in the conventional cast material (order of $10^{12} \mathrm{~m}^{-2}$ ). Similarly, the low SF energy (from 20 to $30 \mathrm{mJm}^{-2}$ ) of Ag-based alloys facilitates the formation of a high density of SFs and twins ${ }^{26}$. The SFs/twins have a width of $32 \pm 12 \mathrm{~nm}$, and the distance between them is $113 \pm$ $26 \mathrm{~nm}$. Such a high content of internal defects can be attributed to the non-equilibrium rapid quenching $\left(10^{5}-10^{6} \mathrm{~K} / \mathrm{s}\right)$ that occurs during selective laser melting ${ }^{27-29}$.

Both the microstructural morphology in the submicron regime (precipitates and cellular structures) as well as the high density of internal defects may lead to remarkable properties in the SLM samples compared to those in the cast alloys (Fig. 2b). The SLM material shows a higher strength than its cast counterpart; however, it also has a reduced ductility (Fig. 2a), a yield strength (YS) of $200 \pm$ $5 \mathrm{MPa}$, an ultimate tensile strength (UTS) of $410 \pm 3 \mathrm{MPa}$ and a uniform elongation of $16 \pm 0.5 \%$. The properties of the cast samples (Fig. 2a) are as follows: YS and UTS of $175 \pm 6$ and $340 \pm 8 \mathrm{MPa}$, respectively, with a uniform elongation of $20 \pm 0.7 \%$. The SLM alloy shows a much higher strength than the cast $\mathrm{Ag}-\mathrm{Cu}$ alloys and even a comparable or higher strength than the annealed or aged alloys (Fig. 2b) ${ }^{30-35}$. EBSD analysis reveals that the dislocation density doubles from $\sim 2.5 \times 10^{14} \mathrm{~m}^{-2}$ for the asSLM sample to $\sim 5.0 \times 10^{14} \mathrm{~m}^{-2}$ for the sample after fracture (Supplementary Fig. 11). The dislocation density values suggest that relatively few dislocations are generated during the deformation process and that dislocation movement is hindered by existing internal defects (dislocations, SFs, precipitates and grain boundaries). Hence, there are dislocation tangles along the particles, grain boundaries, SFs and twin boundaries. In addition, additional SFs and twins are also produced during deformation of the Ag matrix, where the twins pass through the precipitates. All these internal defects contribute to the strengthening of the SLM samples. The high strength can be attributed to the resistance to dislocation slip by the existing dislocations, SFs/ twins, precipitates and grain boundaries during deforma$\operatorname{tion}^{36,37}$. The overall strengthening contributions to the yield strength in the SLM Ag-Cu-Ge (Supplementary Fig. 12) can be estimated to be $\sim 84 \mathrm{MPa}$ from dislocations; $\sim 22 \mathrm{MPa}$ from grain size refinement, SFs and twins; and $\sim 64 \mathrm{MPa}$ from precipitate strengthening (the calculations are included in the Supplementary section).

The SLM sample also shows an acceptable ductility (uniform elongation of $16 \pm 0.5 \%$ ). A high work hardening rate is essential for good uniform elongation because it can help delay the localized deformation stress (necking) under tension ${ }^{38}$. The strain hardening exponent $(n)$ of the cast and SLM samples was calculated using the Holloman-Ludwig equation ${ }^{39}$; however, it is difficult to obtain a single power law fit, which was also found for other additive manufactured materials ${ }^{14}$. Values of $\sim 0.20$ and 0.28 are obtained for the SLM sample at strains of $0.012-0.05$ and $0.05-0.17$, respectively. Values of $\sim 0.16$ and 0.21 are observed for the cast sample at strains of $0.005-0.037$ and $0.037-0.20$, respectively. As shown in Fig. 2c, the SLM sample shows a comparable or slightly higher strain hardening rate than the cast sample. It is known that a high dislocation accumulation capability is necessary to obtain a high work-hardening rate, and having multiple deformation mechanisms is important to obtain a high strain hardening rate at high stress levels. Here, the high density of pre-existing internal defects (dislocations, SFs and twins) plays a critical role in improving the strain-hardening rate. At the initial stage, the dislocations are mainly trapped along the cellular boundaries (which are decorated with a high density of pre-existing dislocations), boundaries of the pre-existing SFs and twins, precipitates and grain boundaries, as seen in Fig. 3, leading to the substantial accumulation of dislocations. During the late stages of deformation, the progressively formed deformation twins in the matrix can reduce the dislocation mean free path and entrap a large number of dislocations, leading to high strain hardening at such high stress levels. This effect by nanoscale deformed twins is also called the "dynamic Hall-Petch" effect ${ }^{40,41}$. This result is also confirmed by the strainhardening exponent $(n)$, where both the SLM and cast samples have a higher value of $n$ at during late deformation stage due to the nanoscale deformed twins. Furthermore, the back stress, which was induced by the heterogeneous dislocation distributions and resultant intragranular residual stresses, was also found to have an important role in improving the strain hardening of additive manufactured materials ${ }^{15}$.

The SLM sample has a higher value of $n$ than the cast sample, which can be explained by the presence of a high density of internal defects, disconnected precipitates, and a hierarchical microstructure (giving back stress) ${ }^{14,15}$, which significantly influence the strain-hardening behavior. An interaction between the nanotwining and the disconnected precipitates is also observed and may contribute to the strain hardening. The twins are generated in the matrix near the grain boundaries (Fig. 3d, e) during deformation, directly penetrate $\mathrm{Cu}$-rich precipitates (twinning is only found in the $\mathrm{Cu}_{5} \mathrm{Ge}$ phase but not in the $\mathrm{Cu}_{3} \mathrm{Ge}$ phase) and became weak afterwards (Fig. 3a, g). The twinning plane in the $\mathrm{Cu}_{5} \mathrm{Ge}$ precipitates is found to be $\{10 \overline{1} 1\}$ with a direction of $<\overline{1} 012>$. Figure $3 f$ shows the 

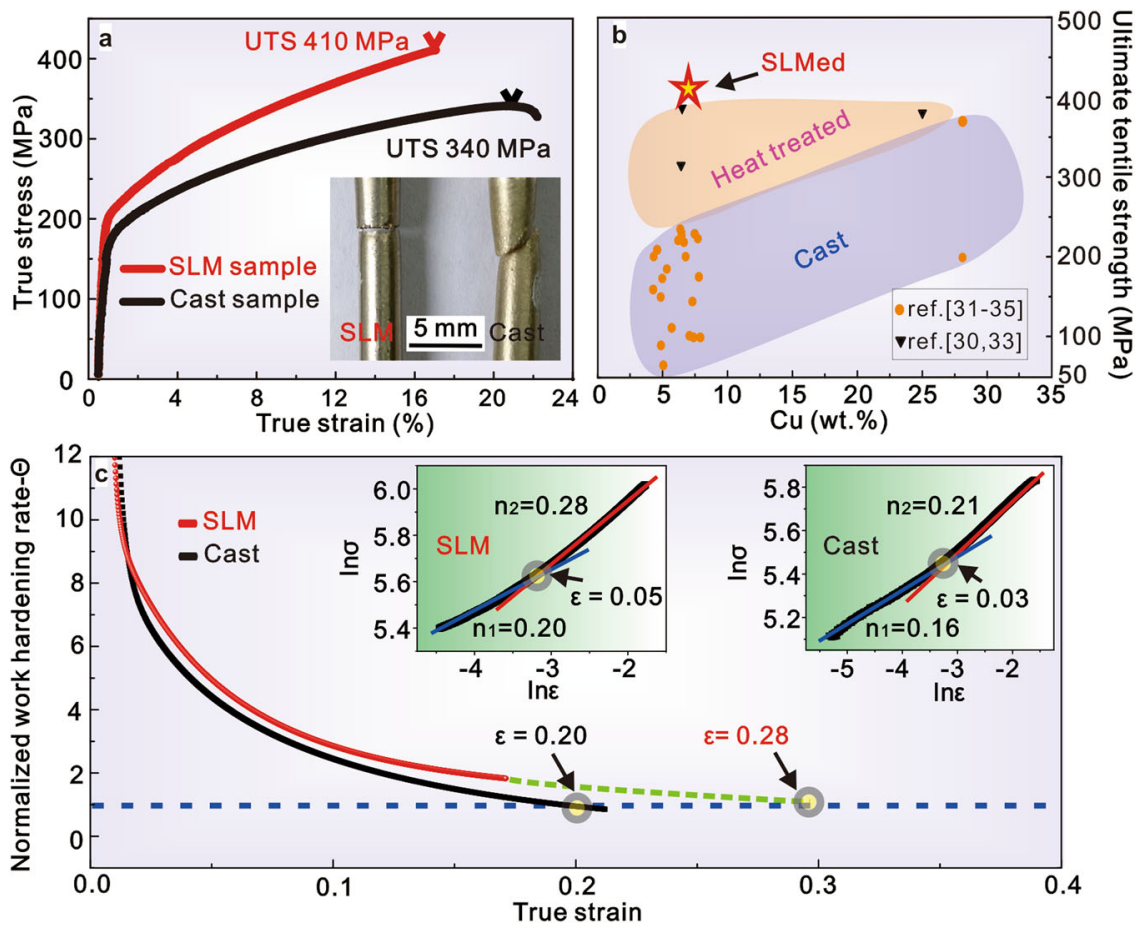

Fig. 2 Mechanical behavior of SLM and cast Ag-Cu-Ge alloys. a True stress vs. true strain curves for the SLM and cast samples. The inset shows the SLM and cast samples after tensile deformation. $\mathbf{b}$ Ultimate tensile strength of the SLM samples compared with the cast and other specimens from the literature. $\mathbf{c}$ Normalized work hardening rate $\left(\Theta=(\partial \sigma / \partial \varepsilon)_{\dot{\varepsilon}} / \sigma\right)^{15,42}$ against true strain for the SLM and cast samples. The dashed lines (green) in c show the possible point satisfying Considère's criterion, where the work hardening rate is equal to true stress. The inset figures in $\mathbf{c}$ are typical In $\sigma-$ In $\varepsilon$ plots for the SLM and cast samples, indicating the strain hardening exponent $n$.

interface between the $\mathrm{Cu}_{5} \mathrm{Ge}$ precipitates and the $\alpha-\mathrm{Ag}$ matrix, indicating that a semicoherent structure with $\{111\} \alpha-\mathrm{Ag}$ is nearly parallel to $\{10 \overline{1} 1\}$ hcp $\mathrm{Cu}_{5} \mathrm{Ge}$, which may help to initiate twinning in the precipitates. In addition, this behavior aids in avoiding premature failure by twinning rather than cracking of the precipitates, which releases the intense local shear stress concentrations near the interface.

Although multiple deformation mechanisms are activated, which would improve the strain hardening behavior, the SLM material fractures before necking. It is clearly observed that no necking occurs from the fracture surface of the tensile tested samples (the inset figure in Fig. 2). According to Fig. 2c, the normalized work hardening curve $(\Theta)$ meets the 1 value at a uniform elongation of $28 \%$ and $20 \%$ for the SLM and cast materials, respectively. Indeed, the cast material shows a uniform elongation of approximately $20 \pm 0.7 \%$ and fractures after reaching a strain of $22 \pm 0.9 \%$. However, the SLM samples only show a uniform elongation of $16 \pm 0.5 \%$ when the fracture occurred. The fracture of the SLM sample is most likely due to premature failure, where a large number of external defects coexist, such as pores and unmelted particles. These external defects could induce stress concentration effects, leading to premature crack initiation, rapid crack propagation and finally acceleration of the cracks to until failure occurs; this trend increases at high stress levels.

The fracture surfaces of the SLM samples show external defects, like pores and unmelted particles (Fig. 4a, f, g), that act as weak spots for crack initiation. Cracks are observed all over the fracture surface (Fig. 4a-g), and most of them initiate from pre-existing external defects. The fracture surfaces do not show an early necking instability. They rather show a mixed mode of failure with both dimples (in the Ag equiaxed grains) (Fig. 4b) and cleavage features (in the columnar grains along the $\mathrm{Cu}$ rich precipitates) (Fig. 4c). Generally, fracture in a material is due to damage accumulation, nucleation of cracks/ voids, and growth/coalescence of cracks/voids, finally leading to failure. However, in the present material, cracks initiate wherever the local stress concentration is high or where the local stresses exceed the fracture strength of the material. Although the precipitates and grain boundaries act as barriers for dislocation and SF/twin movement, the cracks do not originate from or near the precipitates and/ or grain boundaries; hence, Zener-Stroh cracks are absent. The cracks are generated mainly at the external defects, namely pre-existing pores and unmelted particles. The pre-existing pores can be treated as surface cracks 

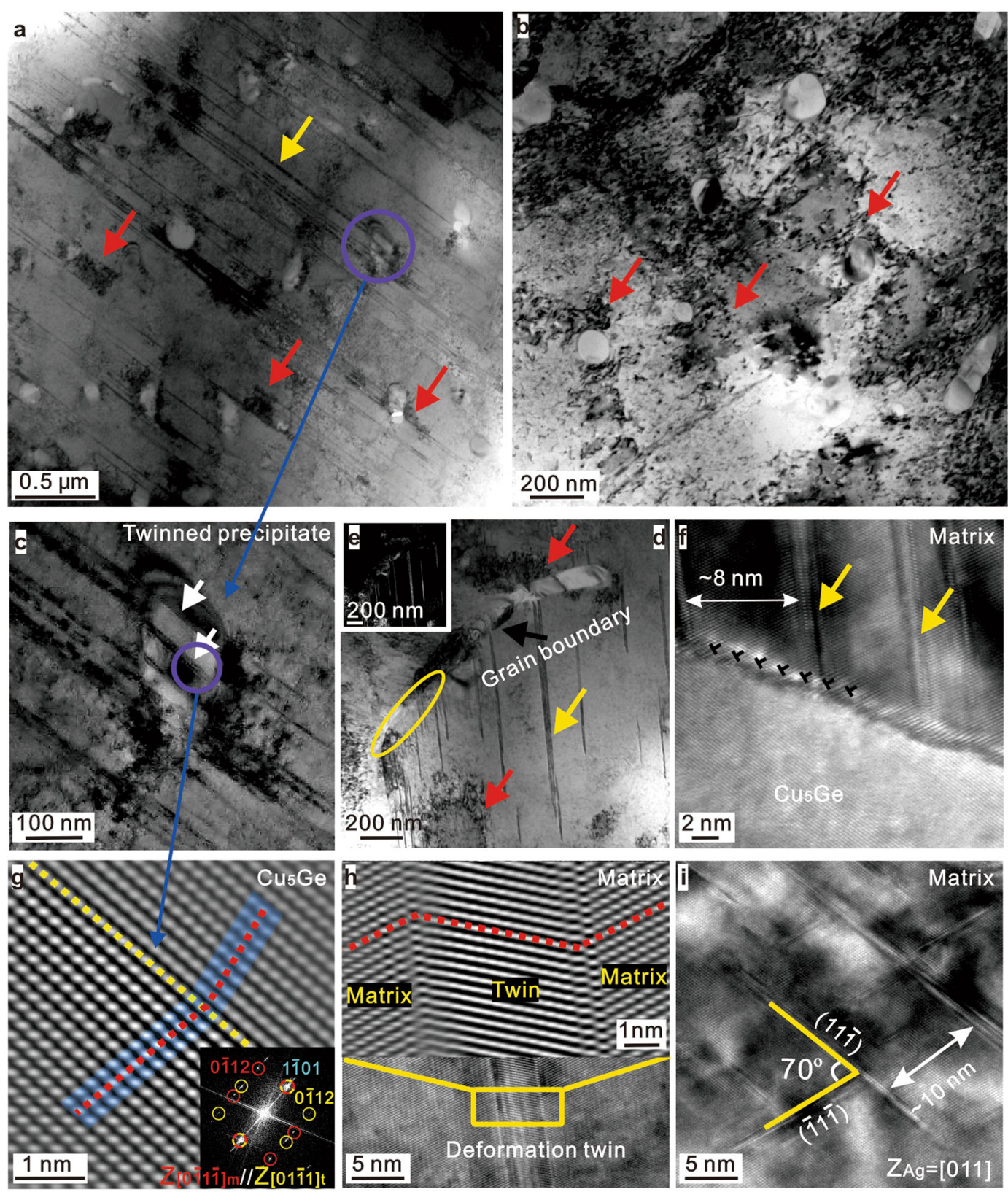

Fig. 3 TEM observations of the SLM Ag-Cu-Ge alloy after tensile deformation. a-c Bright-field (BF) TEM micrographs showing the interaction of Cu-rich precipitates with dislocations, stacking faults (SFs) and twins ${ }^{43-49}$. d BF TEM and e dark-field (DF) TEM images showing the interaction of the grain boundaries with dislocations, SFs and twins. $\mathbf{f}$ HR-TEM micrographs showing the interaction of dislocations, SFs and twins with the interface between the Ag-matrix and Cu-rich precipitates; periodic misfit dislocations are clearly seen. $\mathbf{g}$ HR-TEM micrographs showing twins in the Cu-rich precipitates. h-i HR-TEM micrographs showing SFs and twins in the Ag matrix. Note that the red arrows indicate dislocation tangles, the yellow arrows indicate twins/SFs, and the white arrows indicate twinned precipitates.

(Griffiths theory). During deformation, the local stresses around the pre-existing pores exceed the fracture strength of the material, which cannot withstand further stress. The high stress pileup is relaxed by the nucleation of multiple cracks around the pre-existing pores (Fig. 4f, j).

Similarly, during deformation, unmelted particles (Fig. 4g) that do not have sufficient bonding with the rest of the material undergo particle decohesion. Once the unmelted particles detach from the bulk of the material (when the local stresses exceed the cohesion stress), they create pores/ voids. The pores/voids again act as pre-existing pores and initiate multiple cracks during deformation when the local stress exceeds the fracture strength. Hence, the sources for crack initiation are external defects, namely, pre-existing 

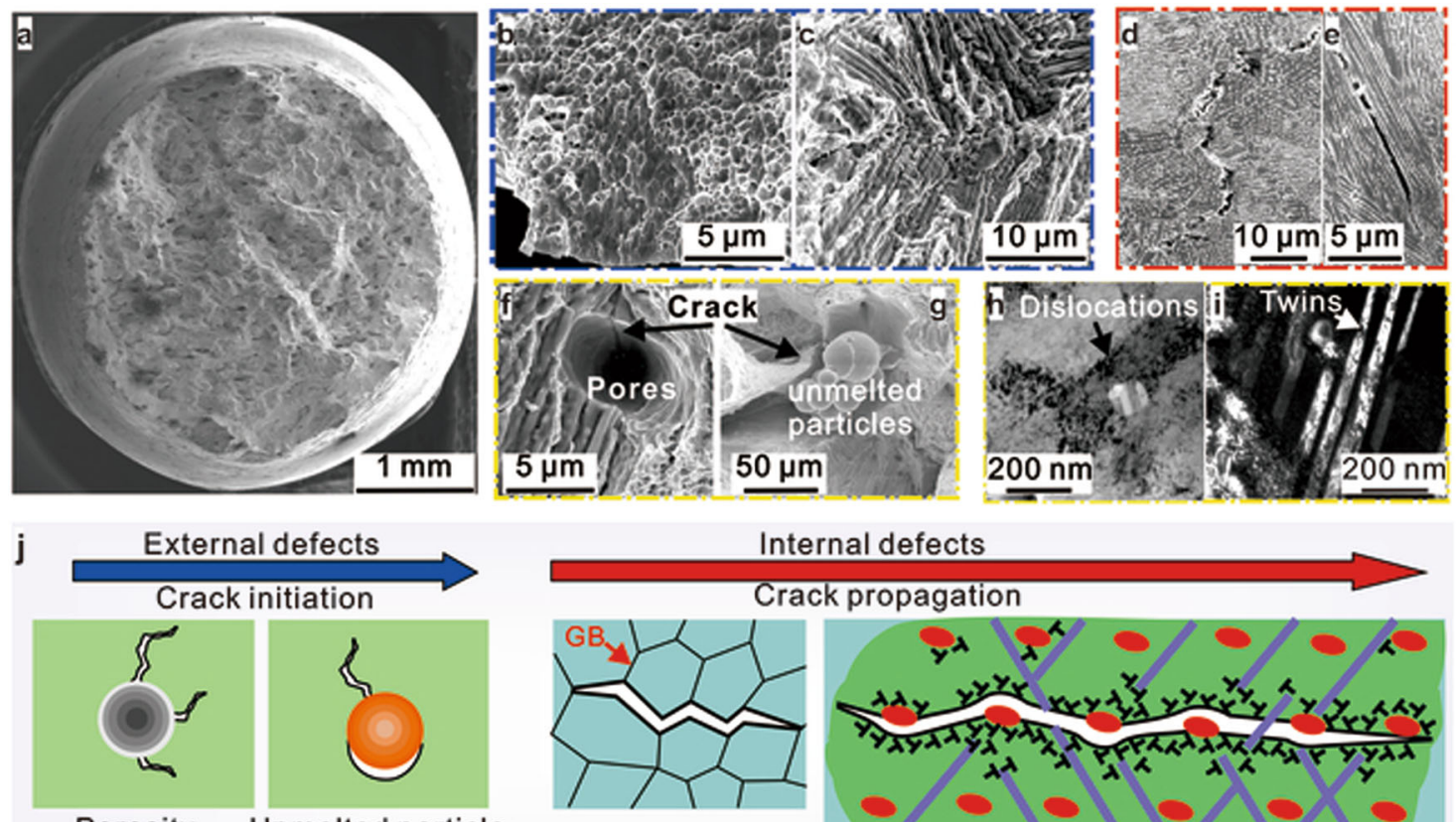

Porosity Unmelted particle

$\approx$ Cracks

Precipitate

$\perp$ dislocations

SFs/Twins

Fig. 4 Hierarchical fracture behavior in the SLM Ag-Cu-Ge alloy. SEM micrographs showing the fracture surface, $\mathbf{b}$, c dimples (in Ag equiaxed grains) and cleavage (in columnar grains) features. $\mathbf{d}$, e SEM micrographs of fractured samples after polishing showing that cracks propagated along the grain boundaries and longitudinal structures. f, g SEM micrographs showing external defects (pores and unmelted particles). $\mathbf{h}, \mathbf{i}$ TEM

micrographs showing internal defects (dislocations, SFs and twins). $\mathbf{j}$ Schematic illustration depicting crack initiation at external defects and crack propagation along internal defects.

pores and unmelted particles, where the local stresses exceed the fracture strength of the material. Once the cracks are initiated at the site of the external defects, premature failure of the material is imminent because crack propagation occurs at much lower stress levels than the initiation of the cracks. The cracks propagate along grain boundaries and precipitates and are aided by internal defects (dislocations, SFs and twins). The concentration of internal defects in the SLM samples is rather high, and the movement of internal defects (dislocations, SFs and twins) is impeded by the presence of precipitates and grain boundaries (Fig. 4h, i). Such blocking of defects increases their concentration (defect density), and the stress concentration increases. A further increase in the stress concentration may lead to nucleation of new cracks. However, cracks readily exist in the SLM material at the pre-existing pores and unmelted particles, and an increase in the density of internal defects along precipitates and grain boundaries aids the motion of the cracks. Hence, the cracks follow areas with a high stress concentration (Fig. 4d, e), i.e., grain boundaries and precipitates present along the longitudinal grains. There are indications that the cracks are arrested and deviated along precipitates and/or grain boundaries, where the density of internal defects is low. However, in general, crack propagation occurs along two regions, namely, the grain boundaries and precipitates, aided by the internal defects (dislocations, SFs and twins).

\section{Conclusions}

The SLM Ag-Cu-Ge alloy herein exhibits an appreciable ductility of $16 \pm 0.5 \%$ (uniform elongation) and an ultrahigh strength of $410 \pm 3 \mathrm{MPa}$ (much higher than those of the cast and annealed alloys). The high strength can be attributed to the resistance to dislocation slip by the existing dislocations, $\mathrm{SFs} / \mathrm{twins}$, precipitates and grain boundaries. A high work hardening rate is observed in the SLM sample, which is essential for obtaining a reasonable uniform elongation, where multiple deformation mechanisms are observed. At the initial stages of deformation, the high strain hardening rate is mainly induced by the substantial accumulation of dislocations by the cellular boundaries, boundaries of the pre-existing SFs and twins, precipitates and grain boundaries. At the late deformation stage, the "dynamic HallPetch" effect induced by the deformation twins plays a major role in producing a high strain hardening at such high stress levels. Furthermore, our strategy reveals that an enhanced strength-ductility synergy can be achieved for SLM alloys with semicoherent precipitates that are 
discontinuous but distributed in a periodic fashion. However, the SLM sample did not show necking, suggesting that the SLM samples may fail prematurely; thus, the full potential deformation has not been realized. Premature failure is most likely induced by external defects, such as pores and unmelted particles. Under ideal conditions, premature failure may be avoided by eliminating pores and unmelted particles and controlling the concentration of internal defects. The formation of the pores may be due to (a) gases adsorbed at powder particles that become entrapped during melting and rapid quenching, (b) improper process parameters and (c) improper exposure of the powder bed to the laser. The formation of the unmelted particles is due to improper exposure of the powder bed to the laser. Careful cleaning of the chamber, an appropriate flow of gases during the process, employing optimized process parameters and using a heat-treated powder without any surface adsorbed gases may suppress the formation of the pores and unmelted particles in the SLM samples, thereby avoiding premature crack initiation and in turn premature failure of the SLM parts. The discovery of this premature failure mechanism provides an opportunity to advance the field of additive manufacturing, where materials with remarkable properties, like an ultrahigh strength and ductility can be fabricated with added functionalities and without theoretical design restrictions.

\section{Acknowledgements}

Research at the South China University of Technology was supported by the Fundamental Research Funds for the Central Universities, a National Natural Science Foundation of China (Grant Nos. 51701075), the Science and Technology Program of Guangzhou (Grant Nos. 201804010365); Research at Tallinn University of Technology was supported by MOBERC15 grant from the European Regional Development Fund. The authors are very thankful to X.L. Xiao for the transmission electron microscopy characterization.

\section{Author details \\ ${ }^{1}$ Guangdong Key Laboratory for Advanced Metallic Materials Processing, South China University of Technology, 510641 Guangzhou, China. ${ }^{2}$ State Key Laboratory of Materials Processing and Die \& Mould Technology, Huazhong University of Science and Technology, 430074 Wuhan, China. ${ }^{3}$ Department of Mechanical and Industrial Engineering, Tallinn University of Technology, Ehitajate Tee 5, 19086 Tallinn, Estonia. ${ }^{4}$ Erich Schmid Institute of Materials Science, Austrian Academy of Sciences, Jahnstraße 12, A-8700 Leoben, Austria. ${ }^{5}$ Department of Materials Science, Chair of Materials Physics, Montanuniversität Leoben, Jahnstraße 12, A-8700 Leoben, Austria. ${ }^{6}$ CBCMT, School of Mechanical Engineering, Vellore Institute of Technology, Vellore, Tamil Nadu 632 014, India}

\section{Author contributions}

Z.W. and K.G.P. conceived and designed the study. Z.W., M.S.X., L.K. and K.G.P. carried out specimen fabrication. Z.W., M.S.X. and K.G.P. carried out the microstructural and mechanical characterization. Z.W. and K.G.P. wrote the paper with support from all authors. All authors considered the results and contributed to the discussion.

\section{Data availability}

All data are available in the main text or the supplementary materials.

Conflict of interest

The authors declare that they have no conflict of interest.

\section{Publisher's note}

Springer Nature remains neutral with regard to jurisdictional claims in published maps and institutional affiliations.

Supplementary information is available for this paper at https://doi.org/ 10.1038/s41427-020-0212-0.

Received: 8 December 2019 Revised: 6 March 2020 Accepted: 11 March 2020.

Published online: 24 April 2020

\section{References}

1. Barriobero-Vila, P. et al. Peritectic titanium alloys for 3D printing. Nat. Commun. 9, 3426 (2018).

2. MacDonald, E. \& Wicker, R. Multiprocess 3D printing for increasing component functionality. Science 353, 1512 (2016).

3. Tofail, S. A. M. et al. Additive manufacturing: scientific and technological challenges, market uptake and opportunities. Mater. Today 21, 22-37 (2018).

4. DebRoy, T. et al. Additive manufacturing of metallic components - process, structure and properties. Prog. Mater. Sci. 92, 112-224 (2018).

5. Gu, D. D., Meiners, W. Wissenbach, K. \& Poprawe, R. Laser additive manufacturing of metallic components: materials, processes and mechanisms. Int. Mater. Rev. 57, 133-164 (2012).

6. Wang, Y. M. et al. Additively manufactured hierarchical stainless steels with high strength and ductility. Nat. Mater. 17, 63-70 (2018).

7. Prashanth, K. G., Scudino, S. \& Eckert, J. Defining the tensile properties of Al12Si parts produced by selective laser melting. Acta Mater. 126, 25-35 (2017).

8. Herzog, D., Seyda, V., Wycisk, E. \& Emmelmann, C. Additive manufacturing of metals. Acta Mater. 117, 371-392 (2016).

9. Martin, J. H. et al. 3D printing of high-strength aluminium alloys. Nature $\mathbf{5 4 9}$ 365-369 (2017)

10. Delahaye, J. et al. Influence of Si precipitates on fracture mechanisms of AlSi10Mg parts processed by selective laser melting. Acta Mater. 175, 160-170 (2019).

11. Prashanth, K. G. Work hardening in selective laser melted Al-12Si alloy. Mater. Des. Process. Comm. 1, e46 (2019).

12. Prashanth, K. G. \& Eckert, J. Formation of metastable cellular microstructures in selective laser melted alloys. J. Alloy. Compd. 707, 27-34 (2017).

13. Chen, B. et al. Strength and strain hardening of a selective laser melted AlSi10Mg alloy. Scr. Mater. 141, 45-49 (2017).

14. Li, Z. et al. Tensile properties, strain rate sensitivity, and activation volume of additively manufactured 316L stainless steels. Int. J. Plast. 120, 395-410 (2019).

15. Chen, W. et al. Microscale residual stresses in additively manufactured stainless steel. Nat. Commun. 10, 4338 (2019).

16. Akhmetova, A. M. et al. Experimental investigations of the Ag-Cu-Ge system. J. Alloy. Compd. 630, 74-77 (2015).

17. Liu, X. et al. High-order hierarchical nanotwins with superior strength and ductility. Acta Mater. 149, 397-406 (2018).

18. Scudino, S. et al. Additive manufacturing of Cu-10Sn bronze. Mater. Lett. 156, 202-204 (2015)

19. Hayes, F. H., Lukas, H. L., Effenberg, G. \& Petzow, G. A thermodynamic optimization of the Cu-Ag-Pd system. Z. Metallkd. 77, 749-754 (1986).

20. Duwez, P., Willens, R. H. \& Klement, W. Jr Continuous series of metastable solid solutions in silver-copper alloys. J. Appl. Phys. 31, 1136-1137 (1960).

21. Spreadborough, J. \& Christian, J. W. High-temperature X-ray diffractometer. J. Sci. Instrum. 36, 116 (1959).

22. Yin, J. et al. Effects of the partial substitutional alloying elements on the crystallization behavior of $\mathrm{Mg}_{65} \mathrm{Cu}_{25} \mathrm{Gd}_{10}$ metallic glass: Ag versus Ni. J. Alloy. Compd. 481, 407-410 (2009).

23. Burkhardt, W. \& Schubert, K. Uber messingartige Phasen mit A3-verwandter Struktur. Z. Metallkd. 50, 442-452 (1959).

24. Schubert, K. \& Brandauer, G. Zum aufbau des systems kupfer-germanium. Z. Metallkd. 43, 262-268 (1952).

25. Prashanth, K. G. et al. Microstructure and mechanical properties of Al-12Si produced by selective laser melting: effect of heat treatment. Mater. Sci. Eng. A. 590, 153-160 (2014).

26. Li, W. et al. Generalized stacking fault energies of alloys. J. Phys. Condens. Matter 26, 265005 (2014) 
27. Sun, Z., Tan, X., Tor, S. B. \& Chua, C. K. Simultaneously enhanced strength and ductility for 3D-printed stainless steel 316L by selective laser melting. NPG Asia Mater. 10, 127-136 (2018).

28. Liu, L. et al. Dislocation network in additive manufactured steel breaks strength - ductility trade-off. Mater. Today 21, 354-361 (2018).

29. Jung, $H$. Y. et al. Fabrication of Fe-based bulk metallic glass by selective laser melting: A parameter study. Mater. Des. 86, 703-708 (2015).

30. Specification, S. Standard specification for $75 \%$ silver, $24.5 \%$ copper, $0.5 \%$ nickel electrical. Contact ASTM Int. 98, 98-100 (2010).

31. Tian, Y. Z. et al. Microstructures, strengthening mechanisms and fracture behavior of Cu-Ag alloys processed by high-pressure torsion. Acta Mater. 60, 269-281 (2012).

32. Tian, Y. Z. \& Zhang, Z. F. Bulk eutectic Cu-Ag alloys with abundant twin boundaries. Scr. Mater. 66, 65-68 (2012).

33. Chairuangsri, T. \& Nisaratanaporn, E. Effects of beryllium on microstructure and resiliency of silver-copper alloy. Chiang Mai J. Sci. 37, 260-268 (2010).

34. Nisaratanaporn, E., Wongsriruksa, S., Pongsukitwat, S. \& Lothongkum, G. Study on the microstructure, mechanical properties, tarnish and corrosion resistance of sterling silver alloyed with manganese. Mater. Sci. Eng. A. 445-446, 663-668 (2007).

35. Nisaratanaporn, S. \& Nisaratanaporn, E. The anti-tarnishing, microstructure analysis and mechanical properties of sterling silver with silicon addition. J. Met. Mater. Min. 12, 13-18 (2003).

36. Wang, Z. et al. Hybrid nanostructured aluminum alloy with super-high strength. NPG Asia Mater. 7, e229 (2015).

37. Shao, $\mathrm{C}$. et al. Architecture of high-strength aluminum-matrix composites processed by a novel microcasting technique. NPG Asia Mater. 11, 69 (2019).

38. Zhao, Y. H., Liao, X. Z., Cheng, S., Ma, E. \& Zhu, Y. T. Simultaneously increasing the ductility and strength of nanostructured alloys. Adv. Mater. 18, 2280-2283 (2006).
39. Campbell, J. E., Thompson, R. P., Dean, J. \& Clyne, T. W. Comparison between stress-strain plots obtained from indentation plastometry, based on residual indent profiles, and from uniaxial testing. Acta Mater. 168, 87-99 (2019).

40. Picak, S. et al. Anomalous work hardening behavior of $\mathrm{Fe}_{40} \mathrm{Mn}_{40} \mathrm{Cr}_{10} \mathrm{CO}_{10}$ high entropy alloy single crystals deformed by twinning and slip. Acta Mater. 181, 555-569 (2019).

41. Laplanche, G., Kostka, A., Horst, O. M., Eggeler, G. \& George, E. P. Microstructure evolution and critical stress for twinning in the CrMnFeCoNi high-entropy alloy. Acta Mater. 118, 152-163 (2016).

42. Akbarpour, M. R. \& Ekrami, A. Effect of ferrite volume fraction on work hardening behavior of high bainite dual phase (DP) steels. Mater. Sci. Eng. A. 477 306-310 (2008).

43. Wang, Y. et al. A low-alloy high-carbon martensite steel with $2.6 \mathrm{GPa}$ tensile strength and good ductility. Acta Mater. 158, 247-256 (2018).

44. Gubicza, J. et al. Microstructure and yield strength of severely deformed silver. Scr. Mater. 58, 775-778 (2008).

45. Jian, W. W. et al. Ultrastrong Mg alloy via nano-spaced stacking faults. Mater. Res. Lett. 1, 61-66 (2013)

46. Gladman, T. Precipitation hardening in metals. Mater. Sci. Technol. 15, 30-36 (1999).

47. Smith, D. R. \& Fickett, F. R. Low-temperature properties of silver. J. Res. Natl Inst Stand. Technol. 100, 119-171 (1995).

48. He, J. Y. et al. A precipitation-hardened high-entropy alloy with outstanding tensile properties. Acta Mater. 102, 187-196 (2016).

49. Calcagnotto, M., Ponge, D., Demir, E. \& Raabe, D. Orientation gradients and geometrically necessary dislocations in ultrafine grained dualphase steels studied by 2D and 3D EBSD. Mater. Sci. Eng. A. 527, 2738-2746 (2010) 